\title{
A bulk and localised electrochemical assessment of epoxy-phenolic coating degradation
}

DOI:

10.1016/j.porgcoat.2016.04.042

\section{Document Version}

Accepted author manuscript

Link to publication record in Manchester Research Explorer

\section{Citation for published version (APA):}

Lyon, S., Kefallinou, Z., \& Gibbon, S. R. (2017). A bulk and localised electrochemical assessment of epoxyphenolic coating degradation. Progress in Organic Coatings, 102, 88-98.

https://doi.org/10.1016/j.porgcoat.2016.04.042

\section{Published in:}

Progress in Organic Coatings

\section{Citing this paper}

Please note that where the full-text provided on Manchester Research Explorer is the Author Accepted Manuscript or Proof version this may differ from the final Published version. If citing, it is advised that you check and use the publisher's definitive version.

\section{General rights}

Copyright and moral rights for the publications made accessible in the Research Explorer are retained by the authors and/or other copyright owners and it is a condition of accessing publications that users recognise and abide by the legal requirements associated with these rights.

\section{Takedown policy}

If you believe that this document breaches copyright please refer to the University of Manchester's Takedown Procedures [http://man.ac.uk/04Y6Bo] or contact uml.scholarlycommunications@manchester.ac.uk providing relevant details, so we can investigate your claim.

\section{OPEN ACCESS}




\title{
A bulk and localised electrochemical assessment of epoxy-phenolic coating degradation
}

\author{
Z. Kefallinou' ${ }^{a}$, S.B. Lyon ${ }^{a}$, S.R. Gibbon ${ }^{b}$ \\ ${ }^{a}$ Corrosion and Protection Centre, School of Materials, University of Manchester, \\ Sackville Street, Manchester, M13 9PL, UK \\ ${ }^{\mathrm{b}}$ Akzo Nobel, Supply Chain, Research \& Development, Stoneygate Lane, Felling, \\ Gateshead, Tyne and Wear, NE10 0JY, UK
}

\section{Abstract:}

Water absorption is believed to be one of the main causes of coating deterioration and degradation. General knowledge dictates that a sudden increase in the coating capacitance, detected during the beginning of immersion, can be attributed to water absorption taking place through the free volume of the polymer. In the examined epoxy-phenolic coating, a quick water saturation state is reached within $24 \mathrm{~h}$ of immersion; however, there is evidence to suggest that water absorption is not the only required factor for corrosion initiation. In the following investigation, the effects of the curing degree, the absorbed water volume, and failure time of intact defect-free coatings were evaluated. A combination of equivalent circuit models were employed to describe the changes taking place across the coating with time. The dielectric properties of the coating material were assessed to account the contribution of the metal-polymer bonds to corrosion protection. Electrochemical Impedance Spectroscopy (EIS) results showed improved coating performance for increased coating curing degree. However, the water content of epoxy-phenolics has 
been increasing with higher coating curing and polymer free volumes, in a combination of dry and immersed testing conditions. Similarly, Localised Electrochemical Impedance Spectroscopy (LEIS) has confirmed water absorption, coating failure and increased coating resistance for highly cured capacitive systems, in the microscale.

\section{Introduction}

Electrochemical Impedance Spectroscopy (EIS) is a widely spread corrosion evaluation tool, established after electrical engineering studies of simple electrical circuits. The use of EIS allows non-destructive electrochemical examination of systems comprising of frequency sensitive electrical elements, like capacitances, resistances and inductions. Common applications include metallic interfaces $[1,2]$, resistive organic coatings $[3,4]$, and membranes [5,6] in a variety of aggressive [7] or inhibiting environments $[8,9]$. Organic coating research has found this technique particularly appealing for estimating coatings life-span [10], physical properties, morphology [11], and for the detection of delamination, like blistering and loss of adhesion [7,12]. However, EIS data interpretation is often misleading, considering that the recorded frequency spectrum corresponds to the averaged current across the whole exposed surface $[13,14]$. Recently developed localised electrochemical impedance spectroscopy (LEIS) has improved understanding of coating systems protection in the microscale [15-17]. The combination of the two techniques offers enriched data analysis and spatial resolution to the complex electrochemical characteristics of a corroding coating surface $[17,18]$.

A big proportion of the ongoing electrochemical research on organic coatings is focused on pre-scribed or defect containing samples, in order to simplify testing 
procedures and analysis, but also to accelerate the corrosion initiation process. Results commonly generate useful empirical knowledge, but our mechanistic understanding is still far from complete. Early researchers have expressed the need to answer simple questions about the onset of coating degradation [19]. This information would reduce time spent on designing and testing new paint formulation recipes, which are required for attaining new resistant coating systems.

Today, it is generally acknowledged that a continuous and uniform coating, unpigmented and free from inherent defects, can protect the underlying substrate by a combination of barrier [20] and adhesive properties [21]. The barrier property of a coating can be described as its ability to hinder water, ions and oxygen permeation through the polymer network. However, it is unclear whether loss of adhesion occurs as a consequence of the presence of aggressive species at the metallic interface, or whether corrosion initiates at regions of reduced adhesion, where enough free metal and electrolyte accumulation can form an electrochemical cell.

Examining coated and free standing film systems, Mayne et al. have come across a specific type of heterogeneity between coating regions, relative to the conductivity of the electrolyte. Regions prone to failure showed coating resistance relative to the chloride content of the electrolyte and were categorised as " $D$ ". On the other hand, the corrosion resistant regions which exhibited the opposite behaviour where labelled as "I" [22-25]. Micro-hardness tests on these regions suggested "D" areas were insufficiently crosslinked regions compared to the "l" [24]. Later researchers, advanced the absorption theory even further suggesting the less crosslinked coating regions, and more "hydrophilic regions", will absorb water preferentially and act as corrosion initiation sites [26]. 
Recent work, published by Morsch et al. on epoxy-phenolic lacquers, showed that prolonged curing at $200{ }^{\circ} \mathrm{C}$ can increase the coating crosslinking degree. Opposite to what is usually described in literature, higher water content was detected under humid conditions on coatings with increased curing degree. This statement, even though contradictory to Nguyen's degradation model, can be attributed to the increasing free-volume introduced in the polymer with further curing, leading to coating swelling, lower coating density and subsequently increased water capacity [27]. Free volume presence in epoxies is responsible for many vital coating properties. For instance, counterintuitively, water volume in epoxies decreases when the coating is exposed to high temperature electrolyte, and vice versa, as the molecular vibrations reduce the available free volume [28]. What is more, polymer rearrangements induced by further curing are also expected to influence the coatings bulk polarity and dielectric constant [29].

In this work, a simplified epoxy-phenolic food can lacquer is used due to its clear, transparent and well defined composition. The lacquer is applied on tin-free (ECCS, Electrolytically Chromium Coated Steel) and traditional tinplates, which are widely used for food can packaging products. Epoxy-phenolics are popular in the food packaging industry for their exceptional adhesion, chemical and electrical resistivity. Their characteristics render them a good choice of barrier coatings for avoiding corrosion caused by the aggressive internal can conditions, but also by hindering metallic contamination of the can content [21,30-32]. Additionally, the absence of inhibiting and other leaching additives, present in most commercially available coating systems, facilitates electrolyte diffusion studies.

The purpose of the applied electrochemical techniques is focusing on detecting and identifying the phenomena before and after coating degradation from the early 
immersion stages, as well as their extent across the microscale. Water content will be estimated through traditional capacitance studies, and the coating performance at different curing degrees will be assessed with respect to the time exposed in the electrolyte. The detection ranges and limitations of each technique will be further analysed. The effect of water content and crosslinking degree on the coating system performance will be used to investigate the above coating degradation theories.

\section{Experimental}

\subsection{Sample Preparation}

Degreased ECCS substrates were used for the application of a lubricant free epoxy-phenolic lacquer, supplied by AkzoNobel N.V. The deposition techniques used for the coatings production was spin-coating at 1000RPM and 2000RPM and bar coating. The samples were then cured in a fan assisted oven at $200{ }^{\circ} \mathrm{C}$ for 10,20 or 30 minutes, for introducing different curing degrees. The lacquer's DSC measurements were previously described by Morsch et al. The lacquer's Tg was shown increasing with longer curing length, but also residual cure that was present in the 10 min samples disappeared after longer curing. Coating samples remained stored in a desiccator at least $24 \mathrm{~h}$ before electrochemical testing. A substrate electrical connection was established and the sample edges were sealed with a mixture of bee wax and colophony (3:1), leaving only $1 \mathrm{~cm}^{2}$ of exposed coating surface. The samples used for localised electrochemical testing were produced similarly and mounted in a Uniscan cell holder.

For the dry EIS measurements, coatings of the same lacquer were produced by spin-coating at 1000RPM on ECCS substrates, followed by direct oven curing at the same temperatures and times. After curing, a Au layer was deposited on the epoxy- 
phenolic surface of each sample, and the sample edges were mechanically cut off to ensure there is no electrical contact between the coating surface and the metallic substrate. This way the dielectric properties of the attached dry polymer film can be assessed, like when placed in a parallel plate electrode setup [33,34].

\subsection{Methods}

\subsubsection{Microscopy}

The produced coatings before and after exposure, their thickness, and the presence of defects, were carried out by means of Scanning Electron Microscopy (SEM, Zeiss EVO-50) at $15 \mathrm{keV}$ electron beam energy. For SEM cross section observations, the coatings surface was covered with a Au layer, to help distinguish the organic coating from the mounting resin. The surface topography of these transparent systems was revealed with a 3D Laser Scanning Microscope (Keyence VK-X210) using a $408 \mathrm{~nm}$ laser beam.

All coatings were inspected with optical microscopy to ensure uniformity. The majority of defects occurring on this coating system were pinholes, caused by the presence of air-bubbles in the lacquer during the coating process. These defects, ranging approximately from $200 \mu \mathrm{m}$ to $25 \mu \mathrm{m}$ in diameter, were easily detected and eliminated from the testing procedure.

\subsubsection{Electrochemical Impedance Spectroscopy}

Electrochemical impedance measurements were recorded at room temperature in the $0.01 \mathrm{~Hz}-10 \mathrm{kHz}$ frequency range using a $10 \mathrm{mV}$ AC perturbation with respect to the open circuit potential of the system, for linearity purposes. Data acquisition required a three electrode setup, consisting of a saturated calomel reference 
electrode $\left(E_{S H E}=E_{S C E}-241 \mathrm{mV}\right.$ at $\left.21{ }^{\circ} \mathrm{C}\right)$ and $\mathrm{Pt}$ ring counter electrode, all enclosed in an earthed Faraday cage. Finally, a Gamry Reference $600^{\mathrm{TM}}$ potentiostat was employed for EIS measurements, in combination with Zview analysis software, by Scribner Associates Inc. The specific equipment was chosen to ensure instrument reliability when measuring highly resistive systems as the specific organic films [35].

Measurements took place immediately after immersion in an aerated $0.1 \mathrm{M} \mathrm{NaCl}$ aqueous solution and were repeated every 2 hours. Those samples which instantly showed a connection to the substrate were excluded from this work. They were supposed to contain defects which allowed electron exchange between the electrolyte and the substrate.

The detected EIS changes with time are typically found in highly resistant intact coating systems when facing gradual degradation with exposure to a corrosive electrolyte [36-38]. The main models describing the coating behaviour are exhibited on Figure 1. The coatings initially exhibited an almost purely capacitive behaviour, and were fitted with model $A$, described by a solution resistance $\left(R_{s}\right)$ and a coating capacitance $\left(\mathrm{C}_{\text {coat }}\right)$. As water absorption is expected to take place through the coatings developing conductive pathways [26], a new resistive component of the impedance is revealed (model $B$ ), corresponding to the coating resistance $\left(R_{\text {coat }}\right)$. What is more, the coating capacitance is no longer represented sufficiently by a pure capacitance, so the dielectric properties of the system are fitted instead using a constant phase element (CPE) [40]. When corrosion initiates (model C), and the current response from the damaged site is high enough to be detected over the averaged surface signal, a second time constant, to represent the metallic surface properties $\left(\mathrm{R}_{\text {corr }}, \mathrm{C}_{\mathrm{dl}}\right)$, is finally recorded. For the purposes of this work, coatings with this type of behaviour are immediately considered failed. 
A

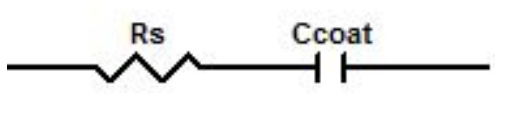

B

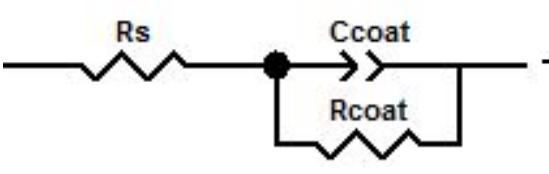

C

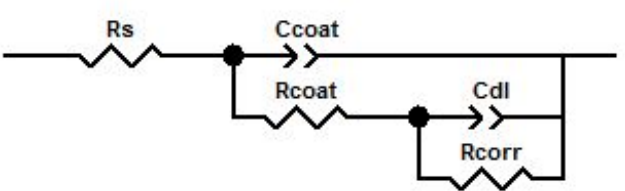

Figure 1: EIS equivalent circuit analysis for $(A)$ Intact, highly capacitive coatings,

(B) Coatings of capacitive and resistive character as they are absorbing electrolyte,

(C) Corroding coatings.

\subsubsection{Water absorption estimation}

A widely spread method for calculating the coating absorbed water volume has been described through the Brasher-Kingsbury equation, according to which the changes in the coating capacitance are related to the amount of water contained in it [41]. The coating capacitance is calculated, as follows:

$$
C_{\text {coat }}=\frac{\varepsilon_{c} \cdot \varepsilon_{o} \cdot A}{t}
$$

where $\varepsilon_{\mathrm{c}}$ is the dielectric constant of the coating, $\varepsilon_{\mathrm{o}}$ the dielectric constant of void $\left(8.85 \cdot 10^{-14}\right.$ Farads $\left./ \mathrm{cm}\right)$, " $\mathrm{A}$ " the exposed area and "t" the coating thickness.

As the amount of contained water in the coating rises $\left(\varepsilon_{\text {water }}=80.10\right.$ at $\left.20^{\circ} \mathrm{C}\right)$, the coating capacitance is shifted to higher values. Thus, by making a series of assumptions on the coating and electrolyte uniformity, the volume of absorbed electrolyte $\left(\Phi_{\mathrm{S}}\right)$ can be calculated as follows [41]:

$$
\Phi_{s}=\frac{\log \left(C_{t} / C_{0}\right)}{\log \varepsilon_{\text {wat }}}
$$

where $\mathrm{C}_{\mathrm{o}}$ and $\mathrm{C}_{\mathrm{t}}$ the coating capacitance at time 0 and time $\mathrm{t}$, respectively. 
The capacitance errors for the data presented in this work were initially around $1 \%$ for all samples and increased up to $3 \%$ with the appearance of the second time constant. The chi-squared values were also maintained low [42]. The development of corrosion sites is increasing the coating fitting uncertainty, since the examined film is no more uniform. On the other hand, when the coating is behaving like a pure capacitor, the coating resistance error is too high to calculate, as the capacitive response is dominating the EIS plot $[14,43,44]$. For this reason, data are fitted with model $A$, until a reasonable resistance error can be calculated. Since capacitance was the most crucial parameter in the water estimation study, the accepted error margins were based on the capacitance values. Nevertheless, the coating resistance error cannot be ignored because when CPE values are converted into Farads, the error propagation can be significant [45]. Replicate samples have been tested for increased statistical confidence [10], and any batch variations have been attributed to the atmospheric conditions during the spin-coating preparation.

To evaluate whether a faster water uptake process exists at the instant of immersion, dry film capacitances have also been calculated with EIS and used as $C_{0}$, for comparison to immersed samples of the same batch. To achieve this, the Au coated polymer film was tightly positioned between two parallel plate electrodes, in order to form an electrical capacitor, as described above. The equipment employed for the capacitance measurements was the same potentiostat in a two electrode arrangement. Each measurement was reproduced three times and appeared stable over a period of 24 hours. All samples presented here exhibited typical pure capacitive behaviour, and the recorded data was corrected for each sample's area. 


\subsubsection{Localised Electrochemical Impedance Mapping}

Localised Impedance mapping was performed at room temperature in a sealed electrochemical cell, to ensure water evaporation is not causing a drift to the map scale. The used LEIS tip consisted of a 100 - $5 \mu \mathrm{m}$ Pt-Ir wire and a ring positioned 3 $\mathrm{mm}$ above the probe tip, which was positioned at a $100 \mu \mathrm{m}$ above the coating surface. The sample was levelled to ensure safe probe scanning across the whole exposed coating region.

The potentiostat used for LEIS measurements was a PAR263A combined with a Solartron 1254 FRA, for the potentiostat signal attenuation. The excitation amplitude produced by the above equipment was set at $10 \mathrm{mV}$, similar to the conventional EIS measurements. The data acquisition and the stage control were achieved through a Uniscan M370 Scanning Electrochemical Workstation and Uniscan LEIS M370 software. Data presented here are converted into admittance values for peak mapping purposes.

Calibration of the LEIS settings took place before experiments in each electrolyte, using a point-in-space (PIS) sample. The PIS sample consisted of a 40 $\mu \mathrm{m} \mathrm{Ag}$ wire mounted in Araldite resin. Localised spectrum recording was essential to achieve a mapping frequency that produces the maximum impedance magnitude contrast between the polymer and the metallic region. LEIS point measurements are much more sensitive to noise compared to traditional EIS, so frequencies below $10 \mathrm{~Hz}$ did not exhibit sufficient stability to be considered reliable.

The electrolyte used in LEIS tests was $50 \mathrm{mM} \mathrm{NaCl}$ solution as high electrolyte conductivities is introducing artefacts that interfere with map analysis. An increased conductivity electrolyte allows a greater number of current pathways to develop in 
the cell, whereas keeping the conductivity low improves spatial resolution, in the expense of signal detection.

\subsubsection{Delamination Resistance}

Cross-hatch testing on intact and sterilised coatings did not induce any significant and quantifiable damage to evaluate coating adhesion to the substrate. However, tests conducted on the same system when applied on traditional tinplate, showed complete coating/substrate detachment when subject to cathodic protection control. Wet adhesion evaluation by cathodic delamination of food can coatings has also been described by other researchers $[21,31]$, as a practical in situ comparison tool.

The complex nature of the interfacial bonds that hold the polymer and the coating together is not yet clearly identified [46]. Metal oxide availability and substrate roughness appear of great importance for coating adhesion and resistance to cathodic delamination $[31,47,48]$. The cathodic delamination effect itself has been commonly attributed to the dissolution of the metal oxide layer, and to alkali attack at the polymer polar groups [49]. Nevertheless, if water and ions are absent at the interface, the formation of an electrochemical cell, and consequently cathodic delamination is not possible. Opposite to dry coating adhesion, which estimates the force required to fracture the metal/oxide/polymer bonds, this type of electrochemical evaluation is an index of the physicochemical resistance of the system.

During delamination resistance tests, $1 \mathrm{~cm}^{2}$ samples were immersed in $5 \% \mathrm{NaCl}$ and set under cathodic potentiostatic control for a number of cycles. After washing and drying, the sample was subjected to a tape test, after leaving the tape attached 
for 2 minutes on the dried coating surface. The delaminated area size was used for comparing the coating resistance to cathodic delamination.

\section{Results}

\subsection{Coating physical characterisation}

The intact coated surface appeared flat and continuous before immersion, as seen on a 10 min cured sample cross section in Figure 2a. Even though the metal substrate roughness was varying significantly for tin-free and traditional tinplate substrates, it does not appear affecting the uniform coverage of the polymer coatings.

With prolonged exposure to the electrolyte, corrosion sites eventually developed where metallic dissolution took place, leading to the perforation of the can substrate (Figure 2b). However, the remaining coating above the corrosion site seems unaffected and only one corrosion site developed. Not all coating samples failed, but on those cases that did degraded, exhibited only one unique corrosion site per sample area examined. Nonetheless, with prolonged immersion the coating appears swelling compared to the initial layer size (Figure 3a), as expected if water is being absorbed through it.

Thickness comparison of coatings with different curing degrees has shown about a $1 \mu \mathrm{m}$ swelling taking place for every extra 10 min curing at $200^{\circ} \mathrm{C}$ (Figure $3 \mathrm{~b}$ ). This effect appears independent of the coating deposition technique. Morsch et al. have attributed this effect to the newly formed bonds between the polymer chains, that hold them further apart, and help create a more rigid and structured polymer network [27]. 

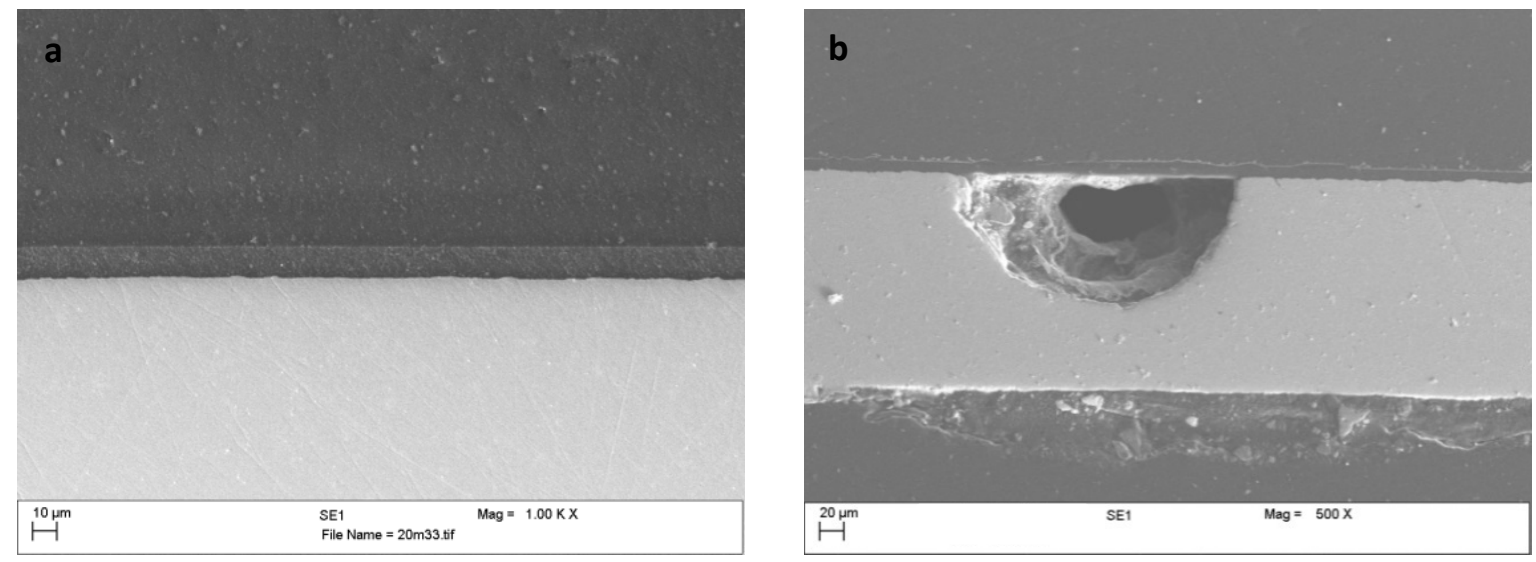

Figure 2: Scanning electron microscopy of (a) an intact epoxy-phenolic coating before immersion and (b) an epoxy-phenolic coating after corrosion site development.

a

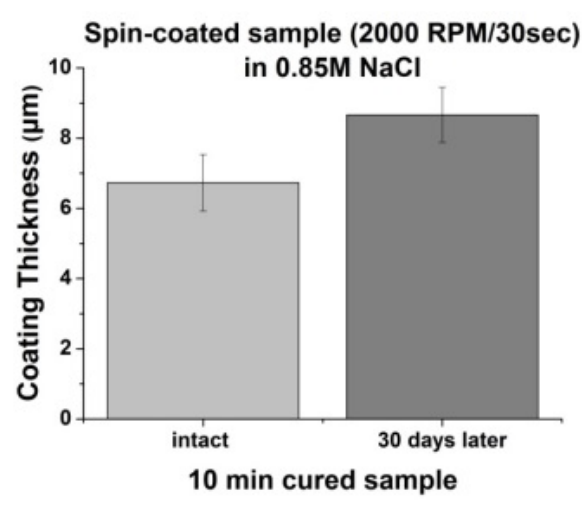

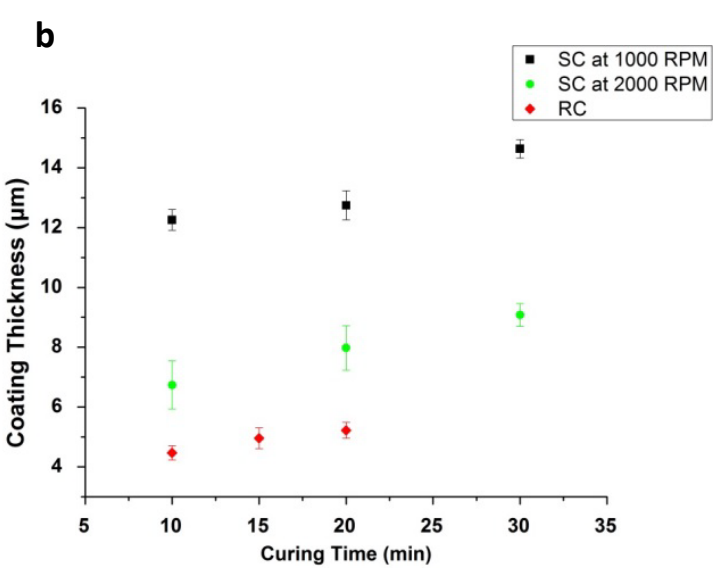

Figure 3: Coating thickness measurements measured by SEM showing coating swelling (a) caused by exposure to the electrolyte and (b) caused by increasing curing time on intact spin-coated (SC) and roller-coated samples (RC). 


\subsection{EIS with exposure time}

The typical Bode and Nyquist plots of a 10 min exposed sample in $0.1 \mathrm{M} \mathrm{NaCl}$ aqueous solution are presented in Figure 4. In the beginning of immersion (Oh), a straight $-90^{\circ}$ line is recorded at the phase angle graph, representing a purely capacitive, frequency independent, coating behaviour. Immediately after immersion (3h), the low frequency region of the phase angle started increasing, due to the formation of transport pathways towards the substrate. As the coatings resistance continued to reduce, the conductive pathways that were created continued developing and interconnecting, till electric contact to the substrate was established. When finally a connection was made (12h), electron exchange took place freely between the substrate and the external electrolyte. As corrosion progressed, the metallic corrosion resistance reduced to lower levels (24h-240h), and the frequency range where the coating response was detected grew smaller. 

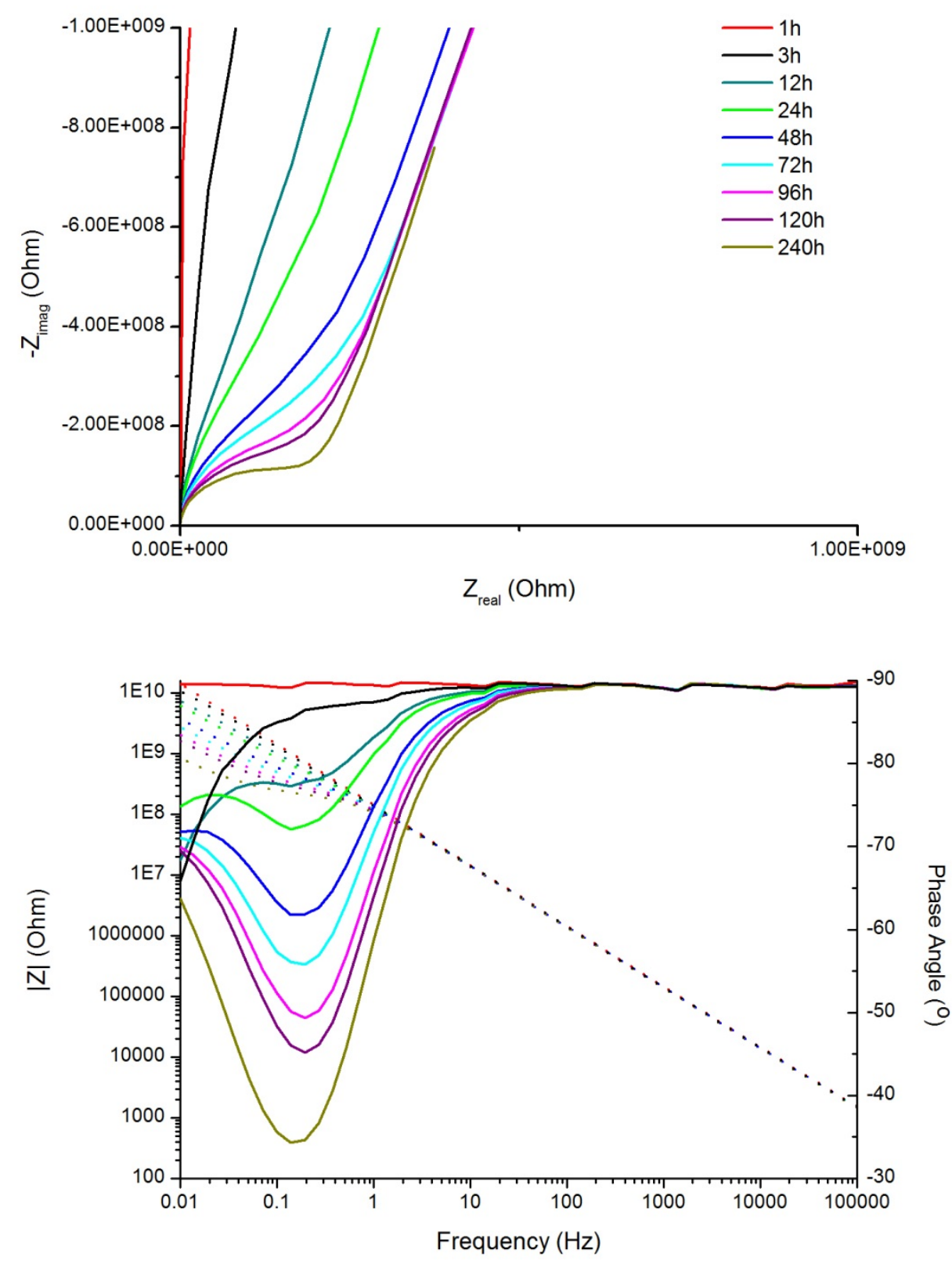

Figure 4: EIS of intact 1000RPM spin-coated epoxy-phenolic coating in $0.1 \mathrm{M} \mathrm{NaCl}$ solution.

\subsection{Coating electrochemical properties}

In Figure 5a, the EIS analysis of two 30 min cured samples produced by spincoated samples is presented. The spin-coating speeds used were 1000RPM, for producing $15 \mu \mathrm{m}$ coating thickness, and 2000RPM for $9 \mu \mathrm{m}$. Coating resistance was 
improved and capacitance showed a reduction, as the coating thickness and the electrolyte diffusion path is extended. However, the water absorption rate, indicated by a sudden resistance decrease and a capacitance rise at the beginning of immersion, is almost identical for the two film thicknesses examined. Both coatings absorption is stabilised after approximately 10 hours of immersion. The estimated water volume by Brasher-Kingsbury equation is between 1 - $2 \%$ of the total coting volume. The second time constant developed only on the thinner sample, and the time it occurred is marked on the plot with a circular point. After corrosion initiation the capacitance error rises significantly, so the water estimation is not as stable and reliable. Van Westing et al. have attributed sudden changes at the coating capacitance just before corrosion initiation to water phase accumulation at the metallic interface, loss of adhesion and heterogeneous coating swelling [50].

Samples of different curing were also examined with EIS and presented in Figure 5b. Analysis proved that increased curing enhances the coating electrical properties. Again the changes in the beginning of immersion are attributed to water absorption that stabilises with time. What is more, the two longer cured samples, 20 and $30 \mathrm{~min}$, did not exhibit corrosion initiation (model $\mathrm{C}$ behaviour) during the test duration, opposite to the 10 min cured sample. The absorbed water volume of the failed sample is in this case rather high due to the greater capacitance error yielded by the fitting. The 20 and 30 min cured samples that remained uniform (model B) during the whole test, both absorbed around $2 \%$ of their volume in water. 
a

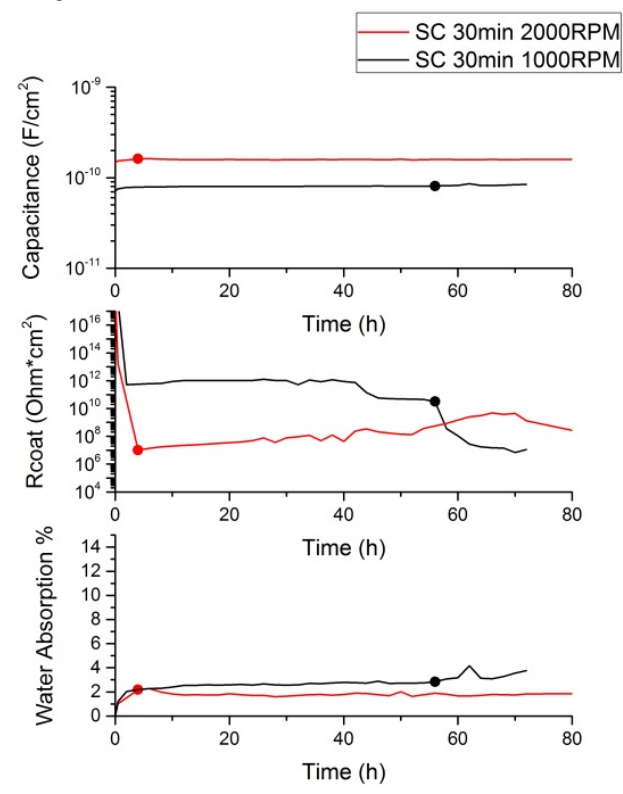

b

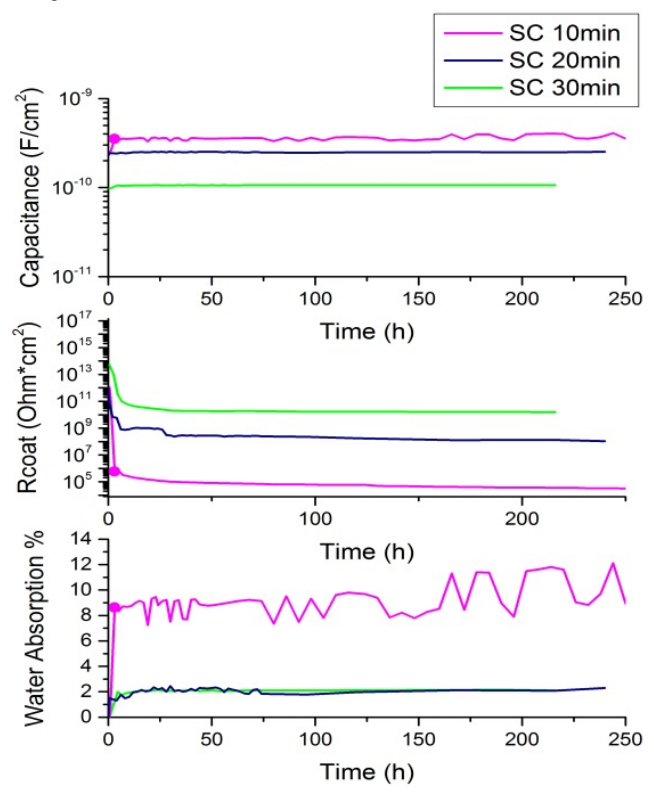

Figure 5: EIS analysis (a) of epoxy-phenolic coatings with different thicknesses and (b) of epoxy-phenolic coatings with different curing degrees.

\subsection{LEIS mapping}

\subsubsection{Monitoring corrosion initiation}

Water absorption and the development of coating failure sites have also been examined with localised electrochemical impedance. In Figure 6, a 2000RPM spincoated and 10 min cured sample that failed rapidly after immersion is shown. The selected mapping frequency was $10 \mathrm{kHz}$. At the beginning of the measurements, the admittance overall the scanned surface was stable and uniform. After two hours of immersion, a sudden increase in the map's admittance was observed in the direction the scan was performed. As the admittance stability was gradually regained, a few higher admittance regions appeared to have developed on the surface and one of them continued growing into a peak, while the rest of the map was still slowly drifting 
to higher admittance values. After 70h of immersion, the peak's intensity decreased, but the overall admittance map did not show any signs of recovery.

To explain the corrosion site deactivation, the samples topography was inspected after immersion, with Laser Scanning Confocal Microscopy (Figure 7). The corrosion site observation revealed large amounts of dense corrosion products overflowing the region, thus obstructing probe current detection. This could indicate that the corrosion process was not continuous, but depended on the geometry of the ruptured coating site and how easily corrosion products could block it. Nevertheless, corrosion product blockage was only temporary and did not lead to anodic activation of new corrosion sites. 

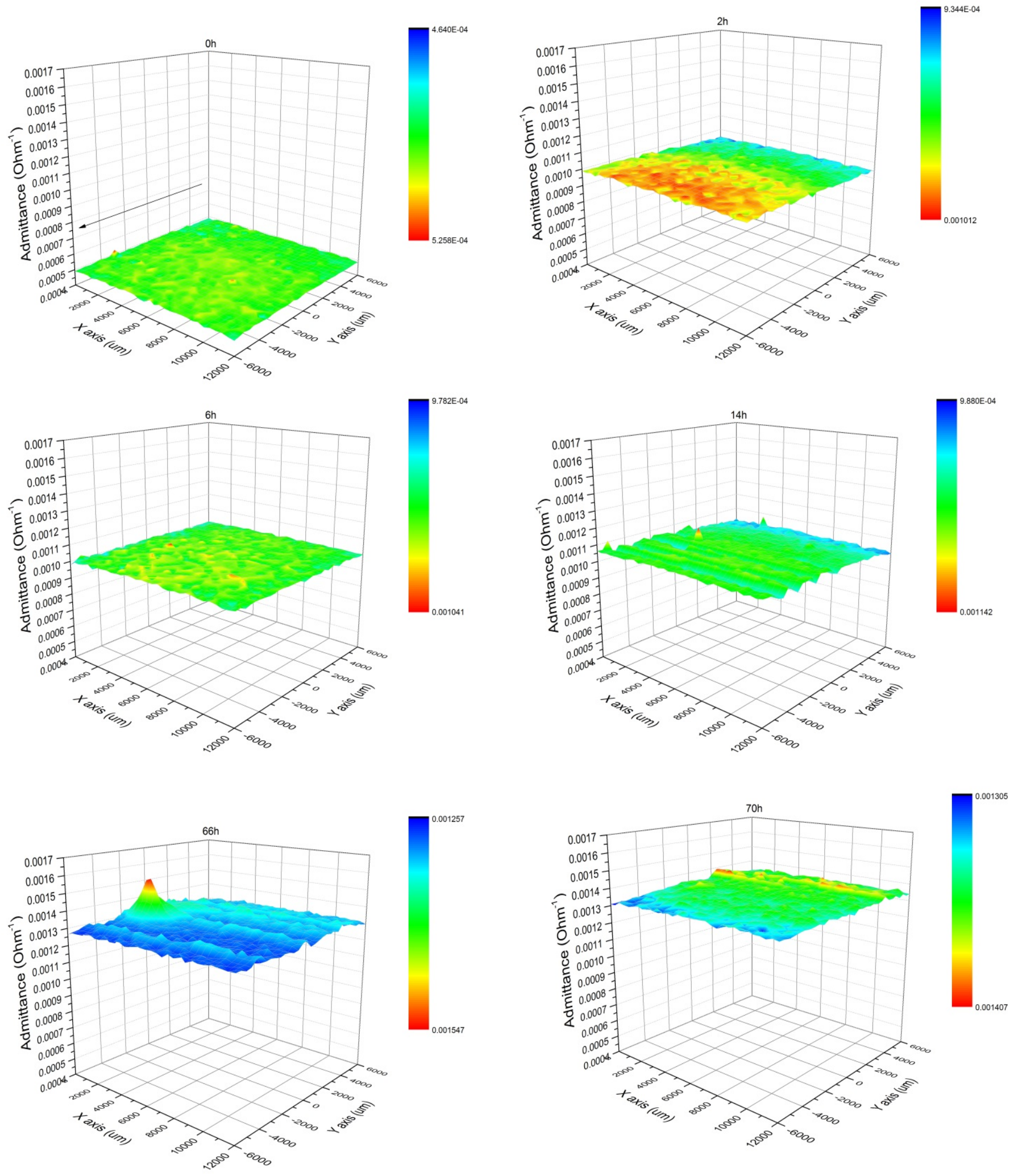

Figure 6: LEIS mapping of degrading 2000RPM spin-coated, 10 min cured epoxyphenolic coating in $50 \mathrm{mM} \mathrm{NaCl}$ solution. 

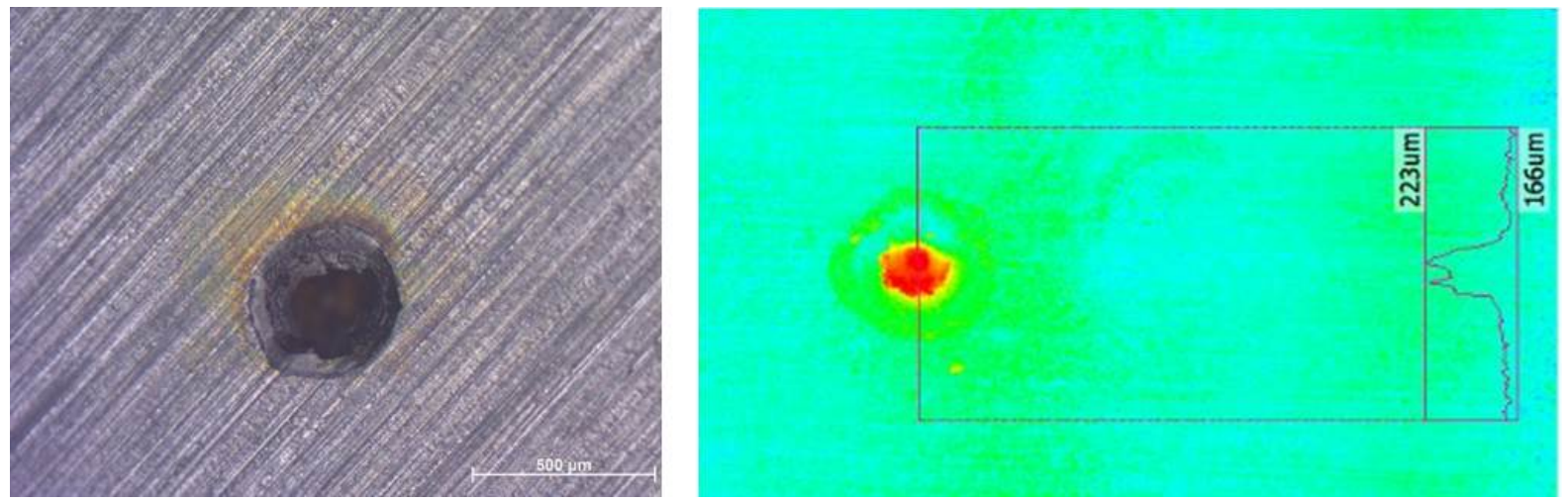

Figure 7: Optical microscopy of corrosion site after LEIS testing (left) and the regions topography (right), attained by laser scanning microscopy.

\subsubsection{Localised comparison of curing degrees}

To achieve a stable state mapping, all samples were compared after 24, 72 and 144 hours of immersion when the water saturation has already occurred (Figure 8). For this comparison, samples that did not exhibit model C behaviour were selected, to guarantee the admittance response is a result of the bulk coating and not caused by the corroding site.

The LEIS curing degree comparison showed that the 10 min samples were less resistive at localised regions at the beginning of immersion, indicated by a sharper profile than the longer cured coatings. With longer exposure the whole signal was further rising to the admittance values of these initial sensitive regions. On the other hand, the longer cured samples, that did not exhibit this type of low resistance peaks, remained stable throughout the duration of the LEIS test. It is suggested that the less cured samples exhibited a more pronounced localised heterogeneity that with further exposure covered the whole map surface. Considering, though, that the presented samples did not show any corrosion signs during testing, the question arises whether this type of heterogeneity was actually destructive. 
$10 \min$
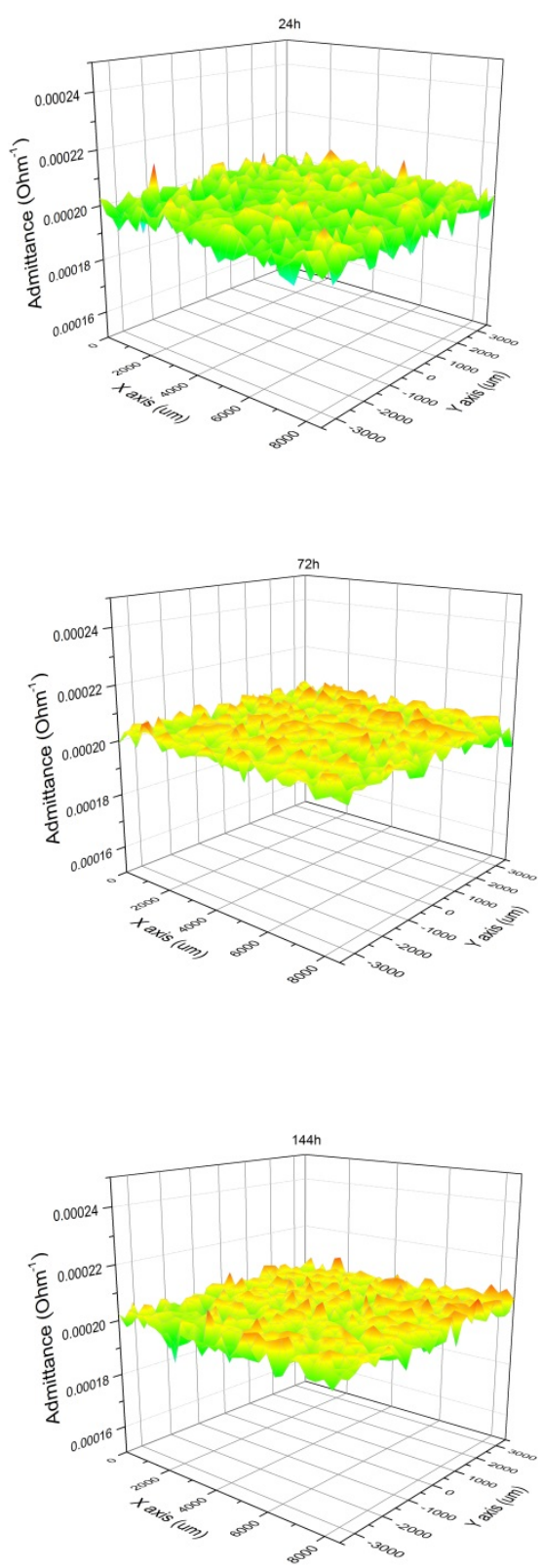

$20 \min$
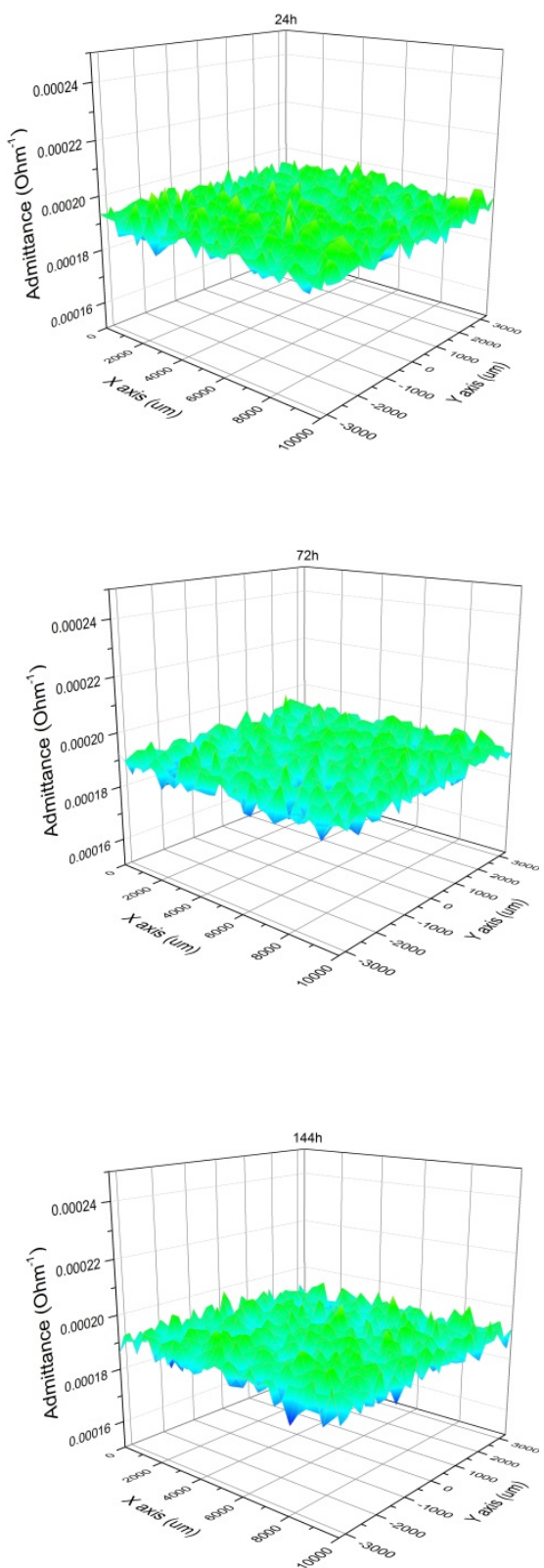

$30 \min$
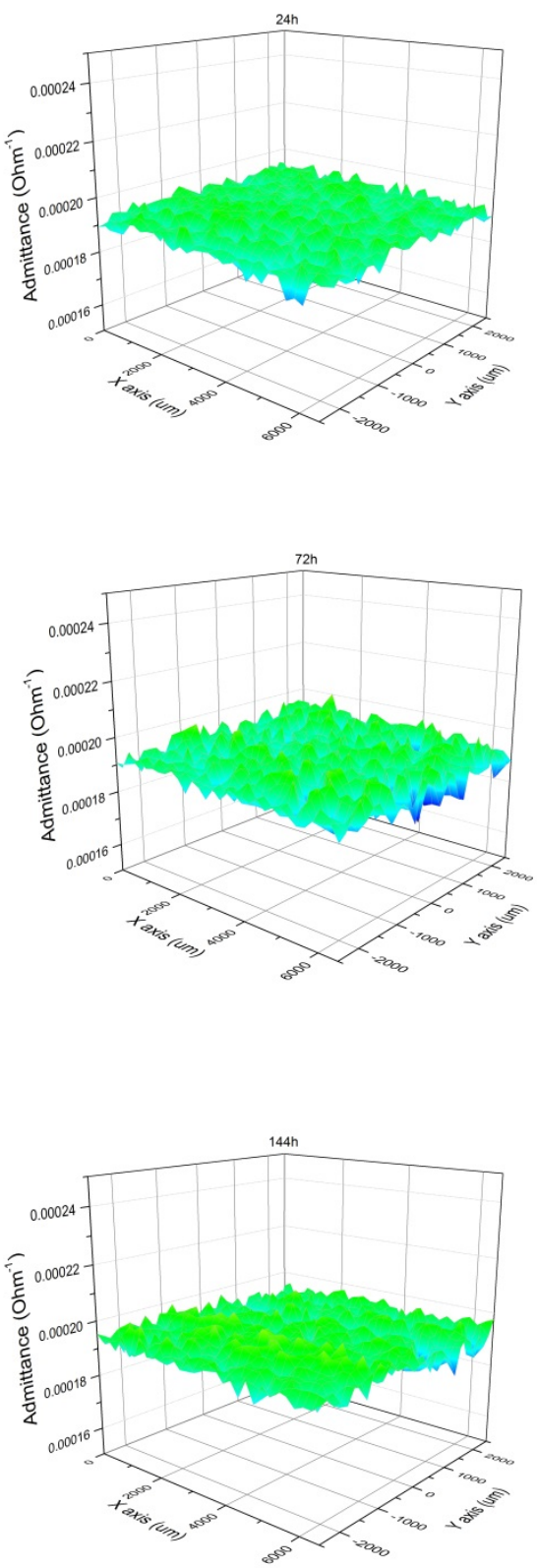

Figure 8: LEIS mapping of capacitive 1000RPM spin-coated epoxy-phenolic coatings with varying curing after 24,72 and $144 \mathrm{~h}$ of immersion. 


\subsection{Dry coating capacitance}

Attached dry coating capacitance measurements were achieved with the use of a plate electrode setup, creating an electrical capacitor. Since corrosion initiation in traditional EIS measurements appeared to interfere with accurate water volume estimation, the samples selected for these tests were only highly capacitive samples, with no signs of corrosion during testing. The dry coating EIS analysis is presented in Figure 9. As in traditional EIS measurements, the capacitance decreased with increasing coating curing, suggesting that measured dielectric properties are intrinsic to the polymer and independent of the electrolyte and testing conditions. The detected capacitance reduction suggests a higher bulk polarity [34] for the longer cured coatings, that could be caused by the chain geometry rearrangements with further curing. The dielectric permittivity of epoxy resins is known to be sensitive to changes with curing time and temperature. Senturia and Sheppard [34] have shown that the dielectric permittivity of DGEBA resins is decreasing with prolonged curing at $137^{\circ} \mathrm{C}$.

For the water volume calculations, coating samples of the same batch, but with no Au platting, were used in traditional EIS measurements. The immersed samples capacitances were also plotted after $24 \mathrm{~h}$ immersion, when the coatings were water saturated (Figure 9). The capacitance error for the dry coating measurements was less than $0.1 \%$, whereas for the immersed samples it did not exceed more than $1 \%$.

The capacitance values presented in Figure 9, were used to recalculate the absorbed water volume through Brasher-Kingsbury's equation, using the dry coating capacitances as $\mathrm{C}_{0}$. Water estimation, in this case, agrees with earlier humidity studies [27], where the longer coating curing yields greater coating water capacity 
(Figure 10). Comparing these water volumes with the ones calculated initially in Figure 5, we can conclude that a much greater water amount is absorbed by a completely dry coating than by a coating that has just been immersed. To avoid confusion, for the purposes of this work, the water volume measured using the completely dry coating state capacitance as $\mathrm{C}_{0}$ will be called $\mathrm{W}_{\text {total }}$, and the water volume estimated from traditional just immersed capacitance measurements will be called $\mathrm{W}_{0}$. The $\mathrm{W}_{\text {total }}$ volume is the sum of the $\mathrm{W}_{0}$ volume plus the volume that can instantly be filled with water.

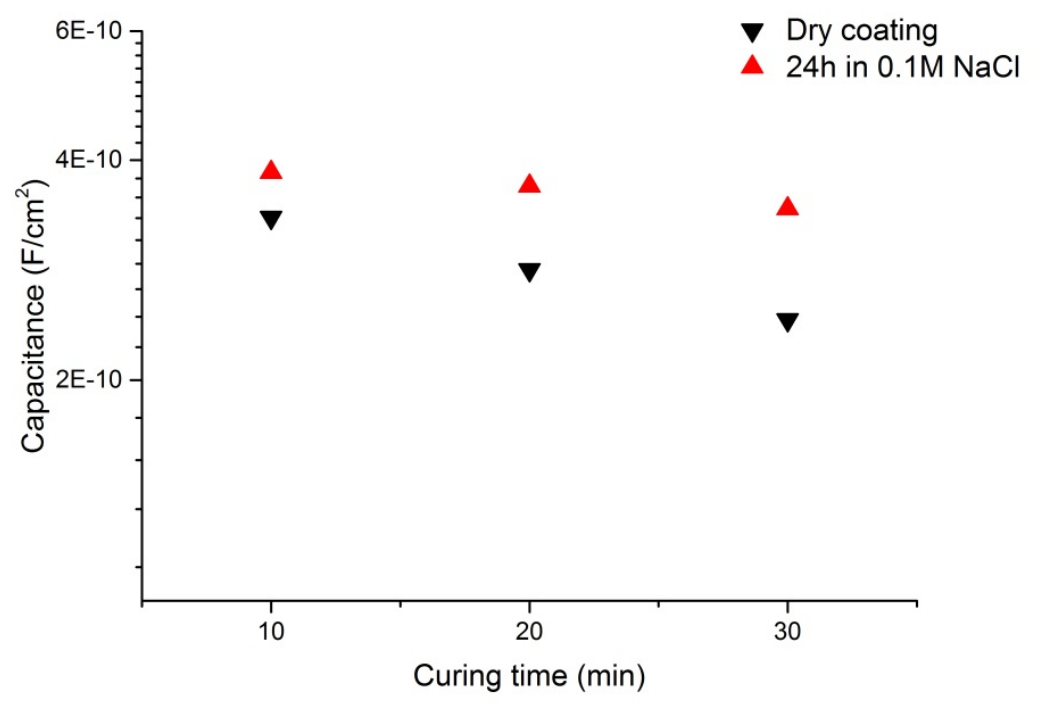

Figure 9: Capacitance of dry epoxy-phenolic films and uncorroded immersed epoxyphenolic coatings after 24 hours immersion in $0.1 \mathrm{M} \mathrm{NaCl}$ solution, when cured for time lengths. 


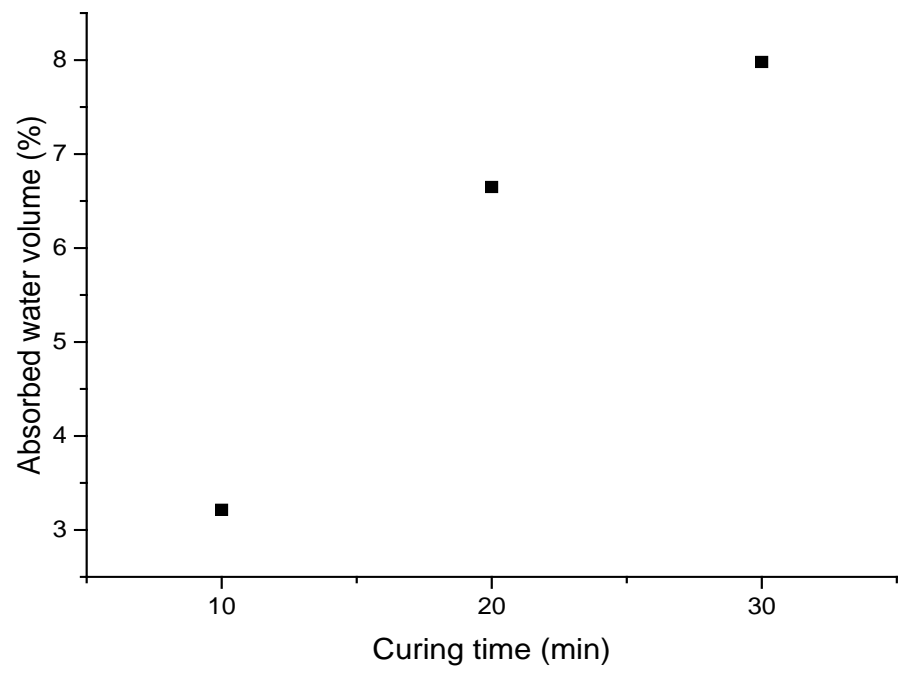

Figure 10: Water volume absorbed through an epoxy-phenolic coating from the completely dry state till complete saturation with different curing degrees.

\subsubsection{Resistance to delamination}

Cathodic polarisations of a 10 and a 30 min cured sample deposited by 1000RPM spin-coating on traditional tinplate were performed at $-3 \mathrm{~V}$ vS $\mathrm{E}_{\mathrm{SCE}}$ in an aqueous $0.85 \mathrm{M} \mathrm{NaCl}$ solution. The testing process took place in AC/DC/AC cycles [ref] consisting of an EIS measurement followed by a 4 hour cathodic polarisation step, a 20min break and another EIS measurement. Delamination was confirmed with the EIS tests that showed model $\mathrm{C}$ behaviour when the coating was detachment begun.

The 10 min sample after only 8 hours of polarisation failed and was removed from the solution for performing a tape test (Figure 11a). On the contrary, the $30 \mathrm{~min}$ sample even after $12 \mathrm{~h}$ of polarisation showed no sign of degradation with EIS and was again removed for performing a tape test (Figure 11b). The tape pull off test showed a small delaminated region on the 10 min cured sample whereas the $30 \mathrm{~min}$ 
sample remained attached through the whole testing procedure. This suggests that the coatings cathodic delamination resistance was enhanced at longer curing times.
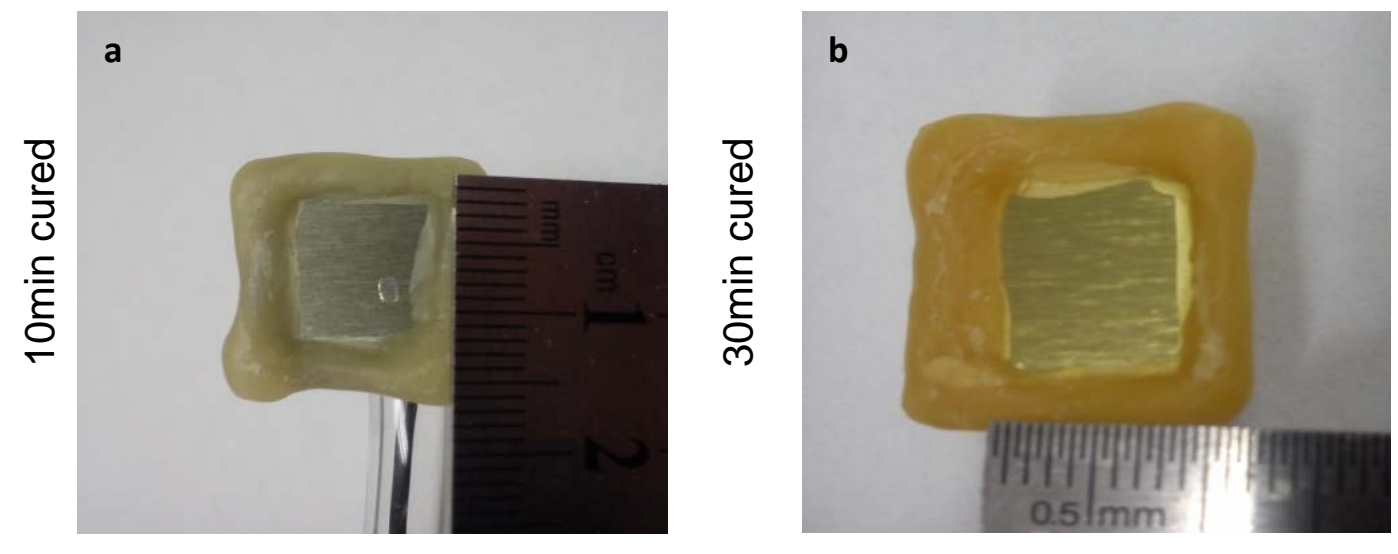

Figure 11: Epoxy-phenolic coatings after cathodic polarisation (a) 10 min cured sample and (b)30 min cured sample.

\section{Discussion}

Coating failure in the examined epoxy-phenolic system developed as unique pitting sites on each sample. At these sites, a direct current to the substrate was available, so that oxidation continued undisrupted while the rest of the coating remained unaffected. As a result, perforation of the substrate was evidenced. LEIS has shown, that if corrosion products grow sufficiently, and in a compact morphology, then the site can be temporarily blocked.

The coating itself has been proved sensitive to swelling as the curing reaction is moving towards completion, as well as with immersion to the electrolyte. The first type of thickness increase was attributed to the higher polymer free volume as the coating curing continued. Whereas immersed coating swelling was a consequence of water absorption between polymer chains. 
EIS analysis showed that the electrochemical properties of the coating were directly linked to coating thickness and curing. The profound importance of coating thickness when comparing samples, can also be seen in LEIS tests, where the mean map admittance of the lower thickness sample (Figure 6) is already much higher than that of the 1000RPM spin-coated samples (Figure 8). Furthermore, as Mayne's work has predicted [24], increased epoxy-phenolics crosslinking enhances coating resistance and time to failure. The reasons behind this curing effect on the coatings corrosion protection were assessed by water uptake estimations and coating delamination tests.

The coating $W_{0}$ water levels, estimated through EIS (Figure 5), showed rapid water diffusion in the polymer in the beginning of immersion, followed by a stable plateau, reached at the coatings full saturation state. Corrosion initiation, though, was not depended on the coatings water content. The amount of water absorbed through the coating was only estimated accurately when the coating retained its uniformity. As can be seen in the 1000RPM sample, which exhibited corrosion initiation after the full coating saturation (Figure 5a), the coating resistance appeared reducing again suddenly when the connection to the substrate was established. Consequently, coating resistance might be a more reliable property for corrosion prediction. This sudden coating resistance drop was not evident in the other two failed samples (SC 30min 2000RPM and SC 10min) because it appeared before the water levels in the coating had stabilised.

These findings suggest that corrosion initiation was not determined only by water presence. Under-film water accumulation can occur significantly at substrate discontinuities produced during the electrodeposition and the coil rolling process [51,52]. Grain boundaries impurities, micro-cracks, metal oxide pores and Lüders 
bands formations are all reasons for insufficient polymer bonding $[53,54]$. The presence of $\mathrm{Cl}^{-}$at such regions can cause metal oxide dissolution [55]. Whether $\mathrm{Cl}^{-}$ ions are similarly efficient at dissolving polymer bound oxides is not clear, but if that is the case, then the $\mathrm{Cl}^{-}$ions arrival at the hydrated polymer/oxide interface can indicate the beginning of oxidation.

When the water volume of the coating was instead calculated from the dry state to the complete saturation, using samples that did not exhibit corrosion initiation, the water content of the coating was increased with better polymer crosslinking. Combining the above water absorption results, three different diffusion mechanisms are proposed. In the dry to water saturated coating tests (Figure 10), the amount of water absorbed $\left(\mathrm{W}_{\text {total }}\right)$ was relative to the coating free volume, and thus increased when the coating was further crosslinked. This absorption step took place instantly with immersion and was not detected with traditional EIS capacitance estimations.

After this instantly available free volume was filled, water kept diffusing through smaller polymer pathways, as indicated during the first hours of immersion by traditional EIS observations (Figure 5). During this step, the intact coatings absorbed approximately a further $2 \%$ of their volume in water, regardless of the coating curing time. This mechanism was fast during the first 10 hours of immersion, but continued slowly until much longer immersion times. This stage could be related to water interrupting polymer bonds and binding to the polymer chains. From more detailed LEIS map comparisons, this slower diffusion step appeared more intense in the case of less crosslinked samples. Both 10 min samples presented here, showed a slow map drifting towards higher admittances, in the presence of corrosion sites (Figure 6) or not (10 min cured sample, Figure 8). This could suggest that polymer network rearrangements were taking place during this time, allowing slightly increased 
amounts of current to pass through the coating. Heterogeneity of epoxy polymers, that could lead to network changes like these, is another controversial issue for coating research, mainly depending on the scale that researchers choose to examine [28,56]. Generally, epoxies are expected to show nanoscale heterogeneities with the form of highly-crosslinked nodular microgel structures in a lower crosslinked matrix $[28,56]$.

Finally, after the establishment of a connection with the substrate, further water absorption and desorption can take place sideways and throughout the defect site and the produced corrosion products. As described previously, effects like these introduce capacitance errors that prevent the accurate use of the BrasherKingsbury's equation.

Whether resistance to delamination was improved due to the prolonged intact behaviour or due to the polarisation itself was not clear. This is because $10 \mathrm{~min}$ samples were more prone to developing two time constants merely as a result of immersion. What is proposed in this paper is that cathodic delamination can cause sufficient chemical attack to the interface, to initiate coating detachment at the case of less cured epoxy-phenolics.

The effect of the substrate finish and electrochemical metallic coating deposition appeared to be of outmost importance for coating, as cathodic delamination was not possible from ECCS substrates. Tin reflow, known for increasing the thickness of the $\mathrm{FeSn}_{2}$ alloy layer, with prolonged exposure at temperatures above the tin melting point $\left(232{ }^{\circ} \mathrm{C}\right)$, can affect tinplate corrosion performance [2]. However, potentiodynamic testing conducted on tinplated substrates heated at $200{ }^{\circ} \mathrm{C}$, excluded such a case. The effects of the metallic surface roughness and the oxide 
layer thickness on the coating delamination resistance were not examined for the purposes of this work, but could be the reason delamination was preferential on tinplate.

The improved delamination resistance of highly cured epoxy-phenolics could be a result of increased interfacial crosslinking. The development of a co-operative type of polymer bonding [57] could explain why longer coating curing reduces the possibility of deadhesion.

\section{Conclusions}

Epoxy-phenolic coatings, in the absence of microscale size defects, can still develop corrosion sites after immersion in $\mathrm{NaCl}$ solutions. The coatings corrosion protection has been related to the coating crosslinking, and to the amount of water present in the coating system, as commonly described in coating failure mechanisms. As the coating curing degree increased, polymer free-volume expanded, leading to swelling, and increased water capacity. In this work, it has been suggested that the corrosion performance of these epoxy-phenolic coatings was retained, not as a result of water present in the polymer, but due to the limited availability of ions and sufficient metallic surface to form an electrochemical cell. The mechanism behind improved coating corrosion performance at higher curing degrees has been suggested to be the enhanced metal polymer bonding, that stopped water and ion contact with the metallic substrate.

LEIS tests have shown the localised nature of corrosion initiation and its development with immersion time. On the contrary, the coating impedance properties and water absorption were recorded taking place uniformly through the whole sample surface. Slow coating rearrangements, causing a gradual impedance 
map drift were only detected on coatings with low crosslinking degrees, whereas longer cured systems remained highly resistive after the initial water absorption step.

\section{Further work}

Ion diffusion through the coating system and electrolyte availability at the metallic interface are factors that require further investigation. Results so far have shown that characterisation of one specific coating property, like the coating water presence, is not sufficient for judging conclusively its corrosion performance. Since all testing techniques are bound by their limitations, a combined thinking approach is required in order to assess the whole organic coating system as a unity.

\section{Acknowledgements}

The authors would like to thank Dr Suzanne Morsch, Dr Stuart Smith, Dr Simon Gibbon and the AkzoNobel Laboratory of Corrosion Protection in the University of Manchester for the useful advice, and acknowledge AkzoNobel for the financial support and the permission to publish this paper.

\section{References}

[1] D. Macdonald, (1978). An Impedance Interpretation of Small Amplitude Cyclic Voltammetry I. Theoretical Analysis for a Resistive-Capacitive System, J. Electrochem. Soc. 125 1443-1449.

[2] X. Huang, F. Lang, Y. Ma, et al., (2014). Effects of reflowing temperature and time on alloy layer of tinplate and its electrochemical behavior in $3.5 \% \mathrm{NaCl}$ solution, Trans. Nonferrous Met. Soc. China. 24 1978-1988.

[3] C. Oliveira, M. Ferreira, (2003). Ranking high-quality paint systems using EIS. Part I: intact coatings, Corros. Sci. 45 123-138.

[4] P.C. Inone, C.M. Garcia, A. Ruvolo-Filho, (2003). Evaluating Barrier 
Properties Of Organic Coatings by Water Permeation And Electrochemical Methods, J. Coatings Technol. Res. 75 29-36.

[5] Y. Gao, W. Li, W.C.L. Lay, et al., (2013). Characterization of forward osmosis membranes by electrochemical impedance spectroscopy, Desalination. 312 $45-51$.

[6] G.L. Coster, T.C. Chilcott, A.C.F. Coster, (1996). Impedance spectroscopy of interfaces , membranes and ultrastructures, 40 79-98.

[7] F. Deflorian, S. Rossi, (2006). An EIS study of ion diffusion through organic coatings, Electrochim. Acta. 51 1736-1744.

[8] I.M. Zin, S.B. Lyon, A. Hussain, (2005). Under-film corrosion of epoxy-coated galvanised steel. An EIS and SVET study of the effectof inhibition at defects, Prog. Org. Coatings. 52 126-135.

[9] M.L. Zheludkevich, D.G. Shchukin, K. a. Yasakau, et al., (2007). Anticorrosion coatings with self-healing effect based on nanocontainers impregnated with corrosion inhibitor, Chem. Mater. 19 402-411.

[10] W. Tait, (2003). Using electrochemical measurements to estimate coating and polymer film durability, J. Coatings Technol. 75 45-50.

[11] K. Jüttner, (1990). Electrochemical impedance spectroscopy (EIS) of corrosion processes on inhomogeneous surfaces, Electrochim. Acta. 35 15011508.

[12] E.A. Papaj, D.J. Mills, S.S. Jamali, (2014). Effect of hardener variation on protective properties of polyurethane coating, Prog. Org. Coatings. 77 20862090.

[13] G. Walter, (1991). The application of impedance spectroscopy to study the uptake of sodium chloride solution in painted metals, Corros. Sci. 32 10411058.

[14] V.S. Bonitz, B.R. Hinderliter, G.P. Bierwagen, (2014). Random and systematic error as a function of sample area in electrochemical impedance spectroscopy data, Prog. Org. Coatings. 77 2100-2106.

[15] F. Zou, D. Thierry, H. Isaacs, (1997). A High Resolution Probe for Localized Electrochemical Impedance Spectroscopy Measurements, J. Electrochem. 
Soc. 144 1957-1965.

[16] J.-B. Jorcin, E. Aragon, C. Merlatti, et al., (2006). Delaminated areas beneath organic coating: A local electrochemical impedance approach, Corros. Sci. 48 1779-1790.

[17] F. Zou, D. Thierry, (1997). Localized electrochemical impedance spectroscopy for studying the degradation of organic coatings, Electrochim. Acta. 423293 3301.

[18] M.C.S.S. Macedo, I.C.P. Margarit-Mattos, F.L. Fragata, et al., (2009). Contribution to a better understanding of different behaviour patterns observed with organic coatings evaluated by electrochemical impedance spectroscopy, Corros. Sci. 51 1322-1327.

[19] W. Funke, (1986). How organic coatings protect against corrosion, in: R.A. Dickie, F.L. Floyd (Eds.), Polym. Mater. Corros. Control, American Chemical Society, Washington DC, : pp. 222-228.

[20] Y. Dong, Y. Zhang, Q. Zhou, (2014). Relationship between ion transport and the failure behavior of epoxy resin coatings, Corros. Sci. 78 22-28.

[21] F. Barilli, R. Fragni, S. Gelati, et al., (2003). Study on the adhesion of different types of lacquers used in food packaging, Prog. Org. Coatings. 46 91-96.

[22] E.M. Kinsella, J.E.O. Mayne, (1969). Ionic Conduction in Polymer Films I. Influence of Electrolyte on Resistance, Br. Polym. J. 1 173-176.

[23] J.E.O. Mayne, J.D. Scantlebury, (1970). Ionic Conduction in Polymer Films II. Inhomogeneous Structure of Varnish Films, Br. Polym. J. 2 240-243.

[24] D.J. Mills, J.E.O. Mayne, (1981). The Inhomogeneous Nature of Polymer Films and its Effect on Resistance Inhibition, in: H.J. Leidheiser (Ed.), Corros. Control by Org. Coatings, NACE International, Texas, : pp. 12-17.

[25] S.S. Jamali, P. Mokhtarian, D.J. Mills, (2015). A probabilistic model for estimation of ionically permeable inhomogeneities in polymer coatings, Prog. Org. Coatings. 87 20-27.

[26] T. Nguyen, J. Hubbard, J. Pommersheim, (1996). Unified model for the degradation of organic coatings on steel in a neutral electrolyte, JCT, J. Coatings Technol. 68 45-56. 
[27] S. Morsch, S. Lyon, P. Greensmith, et al., (2015). Water transport in an epoxy-phenolic coating, Prog. Org. Coatings. 78 293-299.

[28] M.J. Adamson, (1980). Thermal expansion and swelling of cured epoxy resin used in graphite/epoxy composite materials, J. Mater. Sci. 15 1736-1745.

[29] L. Zong, L.C. Kempel, M.C. Hawley, (2005). Dielectric studies of three epoxy resin systems during microwave cure, Polymer (Guildf). 46 2638-2645.

[30] M. Doherty, J.M. Sykes, (2008). A quantitative study of blister growth on lacquered food cans by scanning acoustic microscopy, Corros. Sci. 50 27552772.

[31] A. Nincevic, A. Pezzani, G. Squitieri, (2007). Characterisation of Different Types of Lacquers Used in Food Packaging: Lacquer Adhesion Tests, Acta Aliment. 36 27-37.

[32] L.B. Manfredi, M.J.L. Gines, G.J. Benitez, et al., (2005). Use of epoxyphenolic lacquers in food can coatings: Characterization of lacquers and cured films, J. Appl. Polym. Sci. 95 1448-1458.

[33] J.A. Aukward, R.W. Warfield, (1956). Monitoring Device for Investigation of Encapsulating Resins, Rev. Sci. Instrum. 27 413-414.

[34] S.D. Senturia, N.F. Sheppard, (1986). Dielectric analysis of thermoset cure, in: Adv. Polym. Sci., Springer-Verlag, Berlin, : pp. 1-47.

[35] Gamry Instruments, (2015). Accuracy Contour Plots - Measurement and Discussion.7/10/2015 URL: https://www.gamry.com/applicationnotes/EIS/accuracy-contour-plots-measurement-and-discussion/ .

[36] F. Wormwell, D.M. Brasher, (1947). Electrical Properties of Paint Films on Metals, Nature. 159 678-679.

[37] G. Walter, (1991). The application of impedance methods to study the effects of water uptake and chloride ion concentration on the degradation of paint films-I. Attached films, Corros. Sci. 32 1059-1084.

[38] F. Queiroz, C. Tomachuk, E. Zumelzu, et al., (2012). Effect of Trivalent Chromium Based Treatment on the Protective Properties of Steel Coated with Polymeric Film, ECS Trans. 43 41-44. 
[39] L. Bing, A. Xu, Y. Liang, et al., (2012). Evaluation on Protective Performance of Organic Coatings by Analyzing the Change Rate of Phase Angle at High Frequency, Int. J. Electrochem. Sci. 7 8859-8868.

[40] M.E. Orazem, I. Frateur, B. Tribollet, et al., (2013). Dielectric Properties of Materials Showing Constant-Phase-Element (CPE) Impedance Response, J. Electrochem. Soc. 160 C215-C225.

[41] D.M. Brasher, A.H. Kingsbury, (1954). Electrical measurements in the study of immersed paint coatings on metal. I. Comparison between capacitance and gravimetric methods of estimating water-uptake, J. Appl. Chem. 4 62-72.

[42] G. Spinolo, G. Chiodelli, A. Magistris, et al., (1988). Data Processing for Electrochemical Measurements with Frequency Response Analyzers, J. Electrochem. Soc. 135 1419-1424.

[43] V.S. Bonitz, B.R. Hinderliter, G.P. Bierwagen, (2006). Commercial polymer films as calibration standards for EIS measurements, Electrochim. Acta. 51 3558-3565.

[44] W. Strunz, C. a. Schiller, J. Vogelsang, (2006). The evaluation of experimental dielectric data of barrier coatings in frequency- and time domain, Electrochim. Acta. 51 1437-1442.

[45] D. Nguyen Dang, B. Peraudeau, S. Cohendoz, et al., (2014). Effect of mechanical stresses on epoxy coating ageing approached by Electrochemical Impedance Spectroscopy measurements, Electrochim. Acta. 124 80-89.

[46] J.E. Castle, J.F. Watts, (1985). Interface chemistry of stoved organic coatings, Ind. Eng. Chem. Prod. Res. Dev. 24 361-369.

[47] S.S. Jamali, D.J. Mills, (2014). Steel surface preparation prior to painting and its impact on protective performance of organic coating, Prog. Org. Coatings. 77 2091-2099.

[48] J. Wielant, R. Posner, R. Hausbrand, et al., (2009). Cathodic delamination of polyurethane films on oxide covered steel - Combined adhesion and interface electrochemical studies, Corros. Sci. 51 1664-1670.

[49] H. Leidheiser, W. Wang, L. Igetoft, (1983). The mechanism for the cathodic delamination of organic coatings from a metal surface, Prog. Org. Coatings. 11 
$19-40$.

[50] E.P.M. van Westing, G.M. Ferrari, J.H.W. de Wit, (1994). The determination of coating performance with impedance measurements-III. In situ determination of loss of adhesion, 36 979-994.

[51] E. Zumelzu, C. Angulo, C. Cabezas, et al., (2013). Characterisation of nanometric chromium coatings in metal-polymer composites, Surf. Eng. 29 $620-626$.

[52] E. Zumelzu, C. Cabezas, F. Delgado, (2004). Performance and degradation analyses of traditional and ECCS canning tinplates in citric-citrate medium, J. Mater. Process. Technol. 152 384-388.

[53] J. Li, J. Huang, G. Zhou, et al., (2010). Study on the Growth Mechanism of Electrolytic Chromium Coated Steel (ECCS), Adv. Mater. Res. 154-155 663666.

[54] X. Zhang, B. Boelen, P. Beentjes, et al., (2007). Influence of uniaxial deformation on the corrosion performance of pre-coated packaging steel, Prog. Org. Coatings. 60 335-342.

[55] K. Galić, M. Pavić, N. Ciković, (1994). The effect of inhibitors on the corrosion of tin in sodium chloride solution, Corros. Sci. 36 785-795.

[56] K. Dušek, J. Pleštil, F. Lednický, et al., (1978). Are cured epoxy resins inhomogeneous?, Polymer (Guildf). 19 393-397.

[57] O. Negele, W. Funke, (1996). Internal stress and wet adhesion of organic coatings, Prog. Org. Coatings. 28 258-289. 